
Marsh Sediments

Kendall Valentine

Abbey Hotard

Tracy Elsey-Quirk

Giulio Mariotti

Follow this and additional works at: https://scholarworks.wm.edu/vimsarticles

Part of the Sedimentology Commons 
This manuscript has been submitted for publication in Wetlands. This manuscript has not yet undergone peer review and is a preprint. Subsequent versions of this manuscript may have slightly different content. If accepted, the final version of this manuscript will be available via the 'Peer-reviewed Publication DOI' link on the right-hand side of this webpage.

\section{Benthic biofilm potential for organic carbon accumulation in salt marsh sediments}

\section{Kendall Valentine ${ }^{1,2^{*}}$, Abbey Hotard ${ }^{1,3}$, Tracy Elsey-Quirk ${ }^{1}$, Giulio Mariotti ${ }^{1,4}$}

*Corresponding Author: kvalentine@ vims.edu, ORCiD: 0000-0002-5143-3266, Twitter: @kvalentine_7

ahotard@tamu.edu, tquirk@1su.edu, gmariotti@1su.edu

${ }^{1}$ Department of Oceanography and Coastal Sciences, College of the Coast and Environment, Louisiana State University, Baton Rouge, LA, USA.

${ }^{2}$ Virginia Institute of Marine Science, College of William \& Mary, Gloucester Point, VA, USA.

${ }^{3}$ Department of Marine and Coastal Environmental Science, Texas A\&M Galveston, Galveston, TX, USA.

${ }^{4}$ Center for Computation and Technology, Louisiana State University, Baton Rouge, Louisiana, USA.

\section{Abstract}

Coastal salt marshes are productive environments with high potential for carbon accumulation and storage. Even though organic carbon in salt marsh sediment is typically attributed to plant biomass, it can also be produced by benthic photosynthetic biofilms. These biofilms, generally composed of diatoms and their secretions, are known for their high primary productivity and contribution to the basal food web. In this study, we conducted laboratory experiments to test (1) if biofilms can potentially accumulate carbon in marsh soil and (2) how different sedimentation rates affect the amount of carbon accumulation. Containers filled with a settled mud bed were inoculated with natural biofilms collected from a marsh surface and allowed to grow with favorable light exposure, nutrient supply, and absence of grazing. Mud was added weekly in different amounts, resulting in an equivalent sedimentation rate from 12 to $189 \mathrm{~mm} / \mathrm{yr}$. After 11 weeks, the sediment columns were sampled and analyzed for chlorophyll ( $\mathrm{chl} a$ ), loss on ignition (LOI), and total organic carbon (TOC). Chl $a$ accumulation rates ranged from 123-534 $\mathrm{mg} / \mathrm{cm}^{2} / \mathrm{yr}$, organic matter accumulation ranged from $86-456 \mathrm{~g} / \mathrm{m}^{2} / \mathrm{yr}$, and TOC accumulation rates ranged from $31-211 \mathrm{~g} / \mathrm{m}^{2} / \mathrm{yr}$. All three metrics (chl $a$, organic matter, and TOC) increased with increased sedimentation rate. These results show that biofilms can potentially contribute to carbon accumulation in salt marsh soils. Furthermore, areas with high sedimentation rates have the potential for higher amounts of organic matter from biofilms in the sediment.

\section{Keywords (4-6)}

Microphytobenthos, blue carbon, sedimentation, laboratory experiment, diatoms 
This manuscript has been submitted for publication in Wetlands. This manuscript has not yet undergone peer review and is a preprint. Subsequent versions of this manuscript may have slightly different content. If accepted, the final version of this manuscript will be available via the 'Peer-reviewed Publication DOI' link on the right-hand side of this webpage.

\section{Introduction}

Organic carbon (OC), ubiquitous in wetland soils, is important for food web dynamics

41

42 (rapid carbon dynamics) and carbon sequestration (long-term carbon dynamics). Labile OC serves as the base of the food web, providing nutrients and energy to higher tropic levels (Kwak and Zedler 1997). Additionally, the waterlogged conditions and rapid accumulation of sediments can allow OC, especially recalcitrant carbon, to be buried and stored for significant time periods (Chmura et al. 2003, Dodla et al. 2012, Hopkinson et al. 2012). As a result, coastal salt marshes store up to $1700 \mathrm{~g} / \mathrm{m}^{2} / \mathrm{yr}$ of organic carbon, making them one of the most carbon-rich environments on Earth (Mcleod et al. 2011). Half of all marine carbon burial occurs in wetlands, even though wetlands occupy only $0.2 \%$ of the area available for marine carbon burial (Duarte et al. 2013). Due to the high amount of stored carbon, coastal marshes are considered a blue carbon ecosystem leading to intense study of marsh carbon burial rates over the past several decades (Chmura et al. 2003, Duarte et al. 2005, McLeod et al. 2011, Ouyang and Lee 2014). Most of the carbon found in salt marsh soils has been attributed to plants (macrophytes) (Chmura et al. 2003, Ouyang and Lee 2014). Belowground biomass, in the form of roots and rhizomes, contributes organic carbon directly to sediments, while above-ground biomass can decay on the surface, be exported by tides, or is buried. Although salt marsh plants are probably the main contributor to this carbon pool, algae may be a significant source of organic carbon in salt marsh sediment. Indeed, stable carbon isotopes values of marsh sediments have indicated that a major source of carbon may be from planktonic or benthic photosynthetic microorganisms (Middelburg et al. 1997). Microphytobenthos or biofilms, have been suggested to be a major contributor to the carbon storage in marsh systems (Connor et al., 2001). Additionally, while 
This manuscript has been submitted for publication in Wetlands. This manuscript has not yet undergone peer review and is a preprint. Subsequent versions of this manuscript may have slightly different content. If accepted, the final version of this manuscript will be available via the 'Peer-reviewed Publication DOI' link on the right-hand side of this webpage.

marsh productivity is often driven by plants, gross primary production by biofilms can be similar

to 1.4 times the aboveground production, while Gallagher and Daiber (1974) found that algal

production beneath salt marsh vegetation was $\sim 1 / 3$ of the net production by the plants. zones worldwide (Decho 2000). Living biofilms, because of their light requirements, are limited to the top several millimeters of the sediment surface, but have been shown to have some vertical motility (MacIntyre et al. 1996, Kingston 1999).

The net primary production of biofilms may be greater than $90 \%$ of their gross primary

71 production (Pomeroy 1959), suggesting that most of the carbon biofilms create is not respired,

72 but instead is available for decomposition, transfer to other trophic levels, or burial. Although the 73 organic material produced by biofilms, particularly the EPS, is relatively labile compared to

74 marsh plants (McKew et al. 2011), the sheer volume of carbon produced by the rapid turnover

75 rate of these microorganisms may contribute significantly to the marsh sediment carbon pool. In

76 marshes, biofilms are either decomposed by heterotrophic bacteria, buried, resuspended, or

77 consumed by other organisms (Middelburg et al. 2000). Furthermore, biofilms can be a $\mathrm{CO}_{2}$ sink

78 on the sediment surface, suggesting that they can accumulate $\mathrm{C}$ (Chen et al. 2019). Biofilms that

79 are rapidly buried may decompose slower in an anaerobic environment than at the surface,

80 allowing greater carbon preservation. Biofilms exist in a delicate balance with sediment deposition. If sedimentation rates are

82 too low, biofilms will be exposed to oxic conditions, resulting in more rapid decomposition and 83 less burial of carbon. On the other hand, if sediment deposition rates are too high, biofilms may 
This manuscript has been submitted for publication in Wetlands. This manuscript has not yet undergone peer review and is a preprint. Subsequent versions of this manuscript may have slightly different content. If accepted, the final version of this manuscript will be available via the 'Peer-reviewed Publication DOI' link on the right-hand side of this webpage.

84 be buried, unable to reach the surface and photosynthesize, fix carbon, and reproduce (Miller et al. 1996, Jesus et al. 2009, Pivato et al. 2019). The existence of a maximum sedimentation threshold for biofilm survival has been postulated even within the context of stromatolite growth

87 (Grotzinger and Knoll 1999), but it has never tested experimentally.

Here we hypothesize that at some intermediate sediment deposition rate, the burial of biofilm OC is maximized. The purpose of this study is twofold. First, we test whether benthic biofilms can accumulate carbon in muddy sediments under favorable conditions (light exposure,

91 nutrient supply, and in the absence of grazing). Second, we test how sedimentation rate affects

92 the rate of biofilm carbon accumulation.

\section{Methods}

\subsection{Laboratory Set Up}

A homogenized bentonite-mud slurry (125 g/L bentonite, 35 psu Instant Ocean seawater) was poured into plastic cylinders (height $=20 \mathrm{~cm}$, diameter $=9.5 \mathrm{~cm}$; Figure 1 ). The cylinders were placed on orbital shakers (orbital diameter $=0.5 \mathrm{~cm}, 100 \mathrm{RPM}$ ) and allowed to settle to create a sediment bed $\sim 10 \mathrm{~cm}$ thick with and overlying water column of $\sim 10 \mathrm{~cm}$. The water column was then exchanged weekly using a peristaltic pump to avoid disturbing the bed surface. $35 \mathrm{psu}$ ), and a diluted f/2 medium (Bigelow Laboratory), which provided the necessary nitrogen

102 (10uM, same order of magnitude as world rivers (Sprague et al. 2011)), phosphorus, silica,

103 vitamins and trace metals for growth (N:P:Si = 24.4:1:2.9). Each cylinder was inoculated with a 104 sample of biofilm scraped from the surface of a salt marsh in Cocodrie, Louisiana (USA). Once 105 inoculated, the cylinders were exposed to a 12-hour light/dark cycle using grow lights 106 (Agrobrite, 120V, $60 \mathrm{~Hz}$ high output fluorescent lighting system). The sides of the containers 
This manuscript has been submitted for publication in Wetlands. This manuscript has not yet undergone peer review and is a preprint. Subsequent versions of this manuscript may have slightly different content. If accepted, the final version of this manuscript will be available via the 'Peer-reviewed Publication DOI' link on the right-hand side of this webpage.

were covered in dark paper to ensure light came only from the provided source. Control

containers did not receive the inoculum, were treated with $150 \mathrm{uL}$ of bleach, and kept in the dark to prevent biofilm growth. The cylinders were kept on the orbital shaker, which provided a gentle agitation and promoted vertical mixing of the water column.

The sedimentation experiment began after the observed colonization of the sediment surface by biofilms (two weeks of growth). A slurry of bentonite clay mixed with the medium was added according to five sedimentation rates (Table 1), ranging from 12 to $189 \mathrm{~mm} / \mathrm{yr}$. These rates represent very high mineral deposition rates compared to field measurements and represent areas such as newly-forming deltas (Shields et al. 2017). Biofilm growth was monitored using a pulse-amplitude modulation (PAM) fluorometer throughout the duration of the experiment. PAM fluorescence values have been used as a proxy for chl $a$ and biomass of biofilms in previous studies (Honeywill et al. 2002, Jesus et al. 2005, Murphy et al. 2009, Orvain et al. 2014), and has the advantage of being not destructive. Thirteen points were measured using PAM fluorescence over a regular grid. The fluorescence values demonstrate relative growth within the experiment, not biomass values. Bed heights were also measured and recorded throughout the experiment.

\subsection{Sampling and Analyses}

After 11 weeks, i.e., one week following the last sedimentation event, the sediment in each cylinder was analyzed to calculate the total amount of organic matter, organic carbon, and chl $a$ accumulated throughout the sediment column. Operationally, these measurements were made by separating the top six centimeters of the sediment column - which encompassed the whole layer in which biofilm grew - into two layers $(0-3$ and 3-6 cm). Each layer was then homogenized and subsampled for bulk density and water content, chl $a$ analysis (EPA Method 445.0), loss on ignition (LOI), and total organic carbon (TOC) (Ramnarine et al. 2011). For LOI 
This manuscript has been submitted for publication in Wetlands. This manuscript has not yet undergone peer review and is a preprint. Subsequent versions of this manuscript may have slightly different content. If accepted, the final version of this manuscript will be available via the 'Peer-reviewed Publication DOI' link on the right-hand side of this webpage. analysis, the samples were burned at $550{ }^{\circ} \mathrm{C}$ (Dean 1974). As bentonite clay has high structural water content (Hoogsteen et al. 2015) and our samples had relatively low amounts of organic matter, the mass lost in the control samples was subtracted from all samples to account for the loss of this structural water during the LOI procedure. The total amount of $\operatorname{chl} a$, organic matter, and carbon in each layer was then summed together and divided by the duration of the experiment and the surface area, thus obtaining accumulation rates per unit of area. The LOI and TOC data were fit according to the form:

$$
C_{a c c}=C_{\max }\left(1-\exp \left(-\frac{D}{a}\right)\right)
$$

where $C_{a c c}$ is the accumulation rate of LOI or TOC, $C_{\max }$ is the maximum rate of accumulation of $\mathrm{OM}$ or $\mathrm{C}$ mediated by sediment deposition, $D$ is the deposition rate, and $a$ is a fitting parameter.

\section{Results}

\subsection{PAM Fluorescence and Vertical Accretion}

Fluorescence values increased approximately two weeks following inoculation in all experiments (Figure 2A). The fluorescence values were variable between containers and over time; however, all containers with inoculum had similar values indicating that biofilm was able to grow in all experiments in a replicable way.

The height of the sediment-water interface in each container demonstrated that the addition of bentonite increased the height of the sediment column and the rate of height increase depended on the amount of sediment added (Figure 2B). The height of the containers increased by $4 \mathrm{~mm}$ to $45 \mathrm{~mm}$, for the lowest and highest mineral sedimentation rate respectively over the 11-week experiment. Following each sediment addition, there was an initial increase in bed height and then a slight decrease due to the consolidation of the added sediment. 
This manuscript has been submitted for publication in Wetlands. This manuscript has not yet undergone peer review and is a preprint. Subsequent versions of this manuscript may have slightly different content. If accepted, the final version of this manuscript will be available via the 'Peer-reviewed Publication DOI' link on the right-hand side of this webpage.

Sediment chl $a$ accumulation rate increased with increasing vertical accretion (Figure

$3 \mathrm{~A})$. The containers with the lowest vertical accretion contained on average $123 \mathrm{mg} / \mathrm{cm}^{2} / \mathrm{yr} \mathrm{C}$ and the containers with the highest vertical accretion rate contained on average $534 \mathrm{mg} / \mathrm{cm}^{2} / \mathrm{yr} \mathrm{C}$.

\subsection{LOI and TOC}

As sedimentation rate increased, more organic matter was stored in the sediments (Figure

3B). The average amount of organic matter for the highest vertical accretion rate was 456

164 The containers with the lowest accretion rates contained $31 \mathrm{~g} / \mathrm{m}^{2} / \mathrm{yr} \mathrm{C}$, while those with the highest accretion rate contained $211 \mathrm{~g} / \mathrm{m}^{2} / \mathrm{yr} \mathrm{C}$.

\section{Discussion}

\subsection{The potential for biofilm carbon accumulation}


This manuscript has been submitted for publication in Wetlands. This manuscript has not yet undergone peer review and is a preprint. Subsequent versions of this manuscript may have slightly different content. If accepted, the final version of this manuscript will be available via the 'Peer-reviewed Publication DOI' link on the right-hand side of this webpage.

The carbon accretion rates (CAR) from this study are comparable with those observed in

marshes worldwide. We found rates of $100-200 \mathrm{~g} / \mathrm{m}^{2} / \mathrm{yr} \mathrm{C}$ with moderate to high accretion rates, while worldwide rates for marshes range from 100-300 g/m²/yr C, depending on the latitude and vegetation type, amongst other variables (Ouyang and Lee 2014). Our results demonstrate that under favorable conditions (light, nutrients, no grazing or competition), biofilms have the potential to produce soil carbon at the same order of magnitude of what is observed in marshes worldwide.

Previous experiments have shown that much of the carbon from biofilms is in the form of extra-polymeric substances (EPS), and that this material is rapidly degraded (Guarini et al. 2000, de Brouwer and Stal 2001). These experiments looked at the surface biofilm and the associated carbon, and not at the biofilm carbon with time or depth. Our experiment did not show the ability to store carbon over decadal to centennial time scales due to logistical restraints. Yet, recent studies (Unger et al. 2016) showed that even labile carbon can be stored at depth and for greater than 50 years in marsh sediment, enhanced by high sedimentation rates.

\subsection{Sedimentation rate increases carbon accumulation}

Our experiment clearly shows that the rate of chl $a$ and carbon accumulation increases with the rate of sedimentation. A possible explanation for this trend is that sedimentation stimulates biofilm production by providing additional nutrients. However, this hypothesis is not likely given the abundance of nutrients in the water column; none of these experiments were nutrient limited and therefore a small increase in nutrients from the addition of bentonite should not have increased carbon production significantly.

Another explanation for the increase in OC accumulation with sedimentation rate is that sedimentation could provide additional space (volume) that the biofilms are able to fill as they 
This manuscript has been submitted for publication in Wetlands. This manuscript has not yet undergone peer review and is a preprint. Subsequent versions of this manuscript may have slightly different content. If accepted, the final version of this manuscript will be available via the 'Peer-reviewed Publication DOI' link on the right-hand side of this webpage.

grow upward towards the light source. Sedimentation necessitates vertical movement by the

photosynthetic organisms, and thus causes an increase in organic matter production (Pinckney and Zingmark 1993). Diatoms have been shown to migrate in sediments in short time frames, largely as a response to light (Paterson 1989, Underwood and Kromkamp 1999). As a mechanism of migration, diatoms use their organic secretions (EPS) to aid in their vertical movement (Underwood et al. 1995, Smith and Underwood 1998). With higher sedimentation rates, the diatoms need to migrate further and therefore secrete more organic material. Furthermore, as diatoms migrate, dead cells remain scattered through the sediment (Debenay et al. 2007); with increased sedimentation and increased migration, the amount of carbon from dead cells would also increase. Ultimately, the more volume of sediment present for biofilms to grow upon leads to higher amounts of organic matter production by the biofilms. rate of production. The physiological state of biofilm changes over time (Sutherland et al. 1998), with lower rates of photosynthesis (Serodio et al. 2005) and higher EPS production for more

212 mature biofilms (Orvain et al. 2003). We find that early in the experiment (days 20-50),

213 fluorescence measurements (i.e. rates of photosynthesis) are equal across sedimentation rates, but 214 late in the experiment (days 50-98), fluorescence values are linearly related to sedimentation rate 215 (Figure 4). In fact, at low sedimentation rates, fluorescence values are lower during the later 216 stage of the experiment, supporting the hypothesis of decreased rates of photosynthesis with time 217 (Serodio et al. 2005). Conversely, with high sedimentation rates, fluorescence rates remain high.

218 Our results suggest that sedimentation may constantly "reset" the biofilm age and allow it to 219 grow as in the early stage of development, allowing for the production of more carbon and increased carbon in the sediments. 
This manuscript has been submitted for publication in Wetlands. This manuscript has not yet undergone peer review and is a preprint. Subsequent versions of this manuscript may have slightly different content. If accepted, the final version of this manuscript will be available via the 'Peer-reviewed Publication DOI' link on the right-hand side of this webpage.

High rates of carbon accumulation have been related to high mineral suspended sediment

222

223

224

225

226

227

228

229

230

231

232

233

234

235

236

237

238

239

240

241

242

243

supply (Connor et al. 2001), and therefore increased marsh accretion rates (Kirwan and

Megonigal 2013). While Connor and others (2001) are reporting CARs from all C sources, they

suggest that at low elevations, where sediment accretion rates are higher, biofilms may be a

factor influencing carbon accumulation. We find in our experiments that $\mathrm{OM}$ from biofilms

agree with the relationship between high suspended sediment, high sedimentation rates, and high rates of OC burial.

\subsection{Limits on C accumulation by biofilms}

The consistent trend in all metrics of biofilm growth (chl $a$, LOI and TOC) confirm that biofilm grown under favorable conditions can maintain itself and even thrive under sedimentation rates nearly 16 times the natural rate along the Gulf Coast (Cahoon et al. 2010). Although our results suggest that a constant level of organic carbon accumulation can be reached for arbitrary high sedimentation rates, this is likely not the case. We expect that there is a sedimentation maximum which the biofilms would not be able to recover from (Grotzinger and Knoll 1999), thus limiting its ability to accumulate carbon. Ultimately, at some deposition rate, the biofilms would not be able to reach the sediment surface, or not be able to colonize, grow and reproduce quickly enough on the surface to contribute to carbon accumulation. At very high sedimentation rates, $\mathrm{OM}$ and $\mathrm{C}$ accretion rates would likely decline quickly as less and less of the biofilm is able to reestablish on the sediment surface.

The limited number of samples and replicates in this experiment make it difficult to draw any statistical conclusions. However, the trend present in all three methods of estimating the productivity of biofilms ( $\operatorname{chl} a$, LOI, and TOC) suggests that higher sedimentation rates do allow for more biofilm growth, more organic carbon, and more organic matter. 
This manuscript has been submitted for publication in Wetlands. This manuscript has not yet undergone peer review and is a preprint. Subsequent versions of this manuscript may have slightly different content. If accepted, the final version of this manuscript will be available via the 'Peer-reviewed Publication DOI' link on the right-hand side of this webpage.

An unexpected result of this experiment was that the biofilms were incredibly resilient and able to grow despite large sedimentation rates. Following each sedimentation event, the biofilms colonized the new sediment-water interface very quickly, within 24-48 hours. Indeed,

247 PAM fluorescence (Figure 2A) did not decrease following the sedimentation events, even though these measurements were taken 24-48 hours following such an event. The mineral sedimentation rates tested in this experiment exceed most sedimentation rates for coastlines worldwide and were done episodically. As the biofilms were able to grow in these extreme conditions, biofilms in nature would likely be able to withstand normal sedimentation, as well as sedimentation from storm events.

\subsection{Consequences for natural systems}

The importance of increased sedimentation rates on the productivity of salt marsh biofilm is particularly relevant for coastal restoration projects. Some methods of marsh restoration

256 projects, including sediment diversions (e.g.: Elsey-Quirk et al. 2019) and thin-layer sediment

257 deposition (e.g.: Ford et al. 1999), involve the introduction of high rates of sedimentation to 258 marshes. For example, in a restored marsh in the Bay of Fundy, high sedimentation rates and 259 high carbon accumulation rates were measured prior to the establishment of marsh vegetation (Wollenberg et al. 2018). Wollenberg and others (2018) suggest that the high $\mathrm{C}$ accumulation

261 prior to vegetation is allochthonous. However, given the results of our experiment, biofilm 262 productivity could explain high rates of carbon accumulation prior to the establishment of marsh 263 vegetation.

While in this study, we focus on the role of biofilm OM in salt marsh sediments, biofilms can also be an important source of $\mathrm{C}$ in tidal flats. There are substantial data gaps in our 
This manuscript has been submitted for publication in Wetlands. This manuscript has not yet undergone peer review and is a preprint. Subsequent versions of this manuscript may have slightly different content. If accepted, the final version of this manuscript will be available via the 'Peer-reviewed Publication DOI' link on the right-hand side of this webpage.

267 possible that these systems may play a large role in coastal carbon storage (Lovelock and Duarte 268 2019). As there is no vascular vegetation, the primary autochthonous $\mathrm{C}$ in tidal flats is biofilms.

Thus, quantifying the amount of $\mathrm{C}$ in tidal flats from biofilms will improve our understanding of this potential carbon sink.

\subsection{Future directions}

Future studies should improve the ability to individuate the source of the carbon in marsh

273 sediments (Macreadie et al. 2019). This could help to quantify the impact of biofilms in terms of

274 OC in nature and reconcile our laboratory results with field results. A combination of

275 approaches, including stable isotopes (Choi et al. 2001, Gebrehiwet et al. 2008, Galvan et al.

276 2008, Tanner et al. 2010), organic biomarkers (Spohn and Giani 2012, Johnson et al. 2019), and

277 environmental DNA (Reef et al. 2017) will yield a better understanding of the source of carbon

278 in marsh sediments (Geraldi et al. 2019). For example, studies that have used an increased suite

279 of isotopic signatures were more successful in identifying biofilms (Moncreiff and Sullivan

280 2001, Hondula and Pace 2014, Duarte et al. 2018). These tools have been primarily used to map

281 out food webs, but expanding their use to identify carbon sources can help quantify the

282 contribution of biofilms to salt marsh carbon in the field.

Furthermore, there is a need to conduct more laboratory experiments including additional

284 factors, such as grazing. Biofilms are an important component of the diet of grazing macrofauna

285 in coastal ecosystems (Daggers et al. 2020). However, while we demonstrate that high

286 sedimentation promotes biofilm $\mathrm{C}$ accumulation, little work has been done on how sedimentation

287 rate affects grazers. In sediment-addition restoration projects, snail growth rates were highest

288 with intermediate sediment addition (Stagg and Mendelssohn 2012). It is unclear whether the

higher sedimentation rates will allow more of the biofilms to be buried and protected from 
This manuscript has been submitted for publication in Wetlands. This manuscript has not yet undergone peer review and is a preprint. Subsequent versions of this manuscript may have slightly different content. If accepted, the final version of this manuscript will be available via the 'Peer-reviewed Publication DOI' link on the right-hand side of this webpage.

grazing, or if bioturbation could increase and overall grazing may increase. The strength and direction of this feedback will impact how much biofilm carbon is able to be stored in salt marsh sediments in real settings.

Another important aspect to investigate is the fate of resuspended biofilms. Previous studies have focused on the transfer of biofilm OM to consumers in the water column and adjacent habitats from consumers (Carlton and Hodder 2003) or resuspension events (Ubertini et al. 2012, Savelli et al. 2019). While it is clear that biofilm resuspension dynamics are important, the ultimate fate of the resuspended biofilm carbon is not well understood. Much of the resuspended biofilm OM is likely consumed or decomposed, but some of the biofilm may be redeposited and subsequently buried and stored in the sediments. For example, recent flume experiments (Chen et al. 2019) found that resuspended biofilms allowed for faster biofilms recovery and suggested that repeated erosion redistributed surface biofilms deeper in the bed. They argued that this is important for sediment stabilization, but we posit that it would also be important for $\mathrm{C}$ storage.

\section{Conclusions}

Benthic biofilms in coastal environments are resilient and able to flourish under high sedimentation rates, given ample nutrients and light. These experiments clearly demonstrate that biofilms have the potential to contribute to carbon accumulation in salt marsh sediments. Based on the results presented here, biofilms have the potential to accumulate as much carbon in soils as what is typically measured in salt marshes. While this carbon is labile and may not be stored on a centennial to millennial timescale, it likely plays an important role in the carbon cycle in the marsh.

All analyses validate our hypothesis that higher sedimentation rates increase biofilm C accumulation. A sedimentation threshold above which biofilms cease to grow and to accumulate 
This manuscript has been submitted for publication in Wetlands. This manuscript has not yet undergone peer review and is a preprint. Subsequent versions of this manuscript may have slightly different content. If accepted, the final version of this manuscript will be available via the 'Peer-reviewed Publication DOI' link on the right-hand side of this webpage.

313 carbon might still exist, but it would be relatively high (i.e., >20 mm/yr). The results of this experiment represent the upper bounds of organic carbon accumulation by biofilms, as they were

315 grown under favorable conditions over a short timescale. Further experiments should quantify

316 the role of grazing in limiting biofilm $\mathrm{C}$ accumulation, and how this effect changes as a function

317 of the sedimentation rate.

319 Declarations

$320 \quad$ Funding

$321 \mathrm{KV}$ was funded by the Louisiana Board of Regents.

\section{Conflicts of interest}

323 The authors declare that they have no conflicts of interest

\section{Availability of data and material}

325 All data generated or analysed during this study are included in this published article [and its 326 supplementary information files].

\section{Code availability}

328 Not applicable

\section{Authors' contributions}

$330 \mathrm{KV}, \mathrm{AH}$, and GM designed the experiment. $\mathrm{KV}$ and $\mathrm{AH}$ conducted the experiment. $\mathrm{KV}$ and $\mathrm{AH}$

331 performed the majority of the analysis. GM and TE-Q provided feedback and comments. AH

332 wrote the initial draft, KV wrote all subsequent drafts.

\section{Acknowledgements}


This manuscript has been submitted for publication in Wetlands. This manuscript has not yet undergone peer review and is a preprint. Subsequent versions of this manuscript may have slightly different content. If accepted, the final version of this manuscript will be available via the 'Peer-reviewed Publication DOI' link on the right-hand side of this webpage.

Many thanks to T. Blanchard, S. Gay, M. Kondrat'yev and A. Cole for laboratory assistance. We

would also like to thank K. Moran and A. Cole for their help in editing the manuscript.

\section{$6 \quad$ References}

Cahoon, D.R., 2010, Sea-Level rise impact on salt marsh processes in the Northeast region, SeaLevel Rise and Salt Marsh Restoration Workshop, NOAA Restoration Center, Gloucester, MA, 14 September 2010.

Carlton, J.T., and J. Hodder, 2003, Maritime mammals: terrestrial mammals as consumers in marine intertidal communities, Marine Ecology Progress Series 256: 271-286.

Chen, S., Chmura, G.L., Wang, Y., Yu, D., Ou, D., Chen, B., Ye, Y., and G. Chen, 2019, Benthic microalgae offset the sediment carbon dioxide emission in subtropical mangrove in cold seasons, Limnology and Oceanography 64(3): 1297-1308.

Chen, X., Zhang, C., Paterson, D.M., Townend, I.H., Jin, C., Zhou, Z., Gong, Z., and Q. Feng, 2019 , The effect of cyclic variation of shear stress on non-cohesive sediment stabilization by microbial biofilms: the role of 'biofilm precursors', Earth Surface Processes and Landforms 44(7): 1471-1481.

Chmura, G.L., Anisfeld, S.C., Cahoon, D.R., and J.C. Lynch, 2003, Global carbon sequestration in tidal, saline wetland soils, Global Biogeochemical Cycles 17(4): 1111. doi:10.1029/2002GB001917

Choi, Y., Wang, Y., Hsieh, Y-P, and L. Robinson, 2001, Vegetation succession and carbon sequestration in a coastal wetland in northwest Florida: evidence from carbon isotopes, Global Biogeochemical Cycles 15(2): 311-319.

Connor, R.F., Chmura, G.L, and C.B. Beecher, 2001, Carbon accumulation in Bay of Fundy salt marshes: Implications for restoration of reclaimed marshes, Global Biogeochemical Cycles, 15: 943-954.

Daggers, T.D., van Oevelen, D., Herman, P.M.J., Boschker, H.T.S., and D. van der Wal, 2020, Spatial variability in macrofaunal diet composition and grazing pressure on microphytobenthos in intertidal areas, Limnology and Oceanography 65(11): 2819:2834.

De Brouwer, J.F.C., and L.J. Stal, 2001, Short-term dynamics in microphytobenthos distribution and associated extracellular carbohydrates in surface sediments of an intertidal mudflat,

Dean, W.E., 1974, Determination of carbonate and organic matter in calcareous sediment and sedimentary rocks by loss on ignition: comparison with other methods, Journal of Sedimentary Petrology 44(1): 242-248.

Debenay, J-P., Jouanneau, J-M., Sylvestre, F., Weber, O., and D. Guiral, Biological origin of rhythmites in muddy sediments of French Guiana, Journal of Coastal Research 236: 1431-1442.

Decho, A.W., 2000, Microbial biofilms in intertidal systems: an overview, Continental Shelf Research 20(10-11): 1257-1273.

Dodla, S.K., Wang, J.J., DeLaune, R.D., 2012. Characterization of labile organic carbon in coastal wetland soils of the Mississippi River deltaic plain: Relationships to carbon functionalities. Science of The Total Environment 435-436, 151-158. 
This manuscript has been submitted for publication in Wetlands. This manuscript has not yet undergone peer review and is a preprint. Subsequent versions of this manuscript may have slightly different content. If accepted, the final version of this manuscript will be available via the 'Peer-reviewed Publication DOI' link on the right-hand side of this webpage.

Duarte, C.M., Delgado-Huertas, A., Anton, A., Carriollo-de-Albornoz, P., Lopez-Sandoval, D.C., Agusti, S., et al., 2018, Stable isotope (d13C, d15N, d18O, dD) composition and nutrient concentration of red sea primary producers, Frontiers in Marine Science 5: 298.

Duarte, C.M., Losada, I.J., Hendriks, I.E., Mazarrasa, I., and N. Marba, 2013, The role of coastal plant communities for climate change mitigation and adaptation, Nature Climate Change 3: $961-968$.

Duarte, C.M., Middelburg, JJ., and N. Caraco, 2005, Major role of marine vegetation on the oceanic carbon cycle, Biogeosciences 2: 1-8.

Elsey-Quirk, T., Graham, S.A., Mendelssohn, I.A., Snedden, G., Day, J.W., Twilley, R.R., Shaffer, G., Sharp, L.A., Pahl, J, and R.R. Lane, 2019, Mississippi river sediment diversions and coastal wetland sustainability: synthesis of responses to freshwater, sediment, and nutrient inputs, Estuarine, Coastal and Shelf Science 221: 170-183.

Ford, MA, Cahoon, D.R., and J.C. Lynch, 1999, Restoring marsh elevation in a rapidly subsiding salt marsh by thin-layer deposition of dredged material, Ecological Engineering 12(3-4): 189-205.

Gallagher, J.L. and F.C. Daiber, 1974, Primary production of edaphic algal communities in a Delaware salt marsh, Limnology and Oceanography 19(3): 390-395.

Galvan, K., Fleeger, J.W., and B. Fry, 2008, Stable isotope addition reveals dietary importance of phytoplankton and microphytobenthos to saltmarsh infauna, Marine Ecology Progress Series 359: 37-49.

Gebrehiwet, T., Koretsky, C.M., and R.V. Krishnamurthy, 2008, Influence of Spartina and Juncus on saltmarsh sediments. III. Organic geochemistry, Chemical Geology 225(1-2): 114-119.

Geraldi, N.R., Ortega, A., Serrano, O., Macreadie, P.I., Lovelock, C.E., Krause-Jensen, D., Kennedy, H., Lavery, P.S., Pace, M.L., Kaal, J., and C.M. Duarte, 2019, Fingerprinting blue carbon: rationale and tools to determine the source of organic carbon in marine depositional environments.

Grotzinger, J.P. and A.H. Knoll, 1999, Stromatolites in Precambrian carbonates: evolutionary mileposts or environmental dipsticks?, Annu. Rev. Earth Planet. Sci. 27: 313-358.

Guarini, J.M., Blanchard, G.F., Gros, P., Gouleau, D., and C. Bacher, 2000, Dynamic model of the short-term variability of microphytobenthos biomass on temperate intertidal mudflats, Marine Ecology Progress Series 291: 291-303.

Hondula, K.L.. and M.L. Pace, 2014, Macroalgal support of cultured hard clams in a low nitrogen coastal lagoon, Marine Ecological Progress Series 498: 187-201.

Hoogsteen, M.J.J, Lantinga, E.A., Bakker, E.J., Groot, J.C.J., and P.A. Tittonell, 2015, Estimating soil organic carbon through loss on ignition: effects of ignition conditions and structural water loss, Ear J. Soil Sci 66:320-328.

Honeywill, C., Paterson, D.M., and S.E. Hagerthey, 2002, Determination of microphytobenthic biomass using pulse-amplitude modulated minimum fluorescence, European Journal of Phycology 37: 485-492.

Hopkinson, C., Cai, W.-J., \& Hu, X. (2012). Carbon sequestration in wetland dominated coastal systems - A global sink of rapidly diminishing magnitude. Current Opinion in Environmental Sustainability, 4(2), 186- 194.

Jesus, B., Brotas, V., Marani, M., and D.M. Paterson, 2005, Spatial dynamics of microphytobenthos determined by PAM fluorescence, Estuarine, Coastal and Shelf Science, 60: 30-42. 
This manuscript has been submitted for publication in Wetlands. This manuscript has not yet undergone peer review and is a preprint. Subsequent versions of this manuscript may have slightly different content. If accepted, the final version of this manuscript will be available via the 'Peer-reviewed Publication DOI' link on the right-hand side of this webpage.

Jesus, B., Brotas, V., Ribeiro, L., Mendes, C.R., Cartaxana, P., and D.M. Paterson, 2009, Adaptations of microphytobenthos assemblages to sediment type and tidal position, Continental Shelf Research 29(13): 1634-1634.

Johnson, J.J., Olin, J.A., and M.J. Polito, 2019, A multi-biomarker approach supports the use of compound-specific stable isotope analysis of amino acids to quantify basal carbon source use in a salt marsh consumer, Rapid Communication in Mass Spectrometry 33: 17811791.

Kingston, M.B., 1999, Effect of light on vertical migration and photosynthesis of Euglena proximo (Euglenophyta), Journal of Phycology 35: 245-253.

Kirwan, M.L, and J.P. Megonigal, 2013, Tidal wetland stability in the face of human impacts and sea-level rise, Nature 504: 53-60.

Kwak, T.J., and J.B. Zedler, 1997, Food web analysis of southern California coastal wetlands using multiple stable isotopes. Oecologia 110: 262-277.

Lovelock, C.E., and C.M. Duarte, 2019, Dimensions of blue carbon and emerging perspectives, Biol. Lett. 15: 20180781.

Lovelock, C.E., and R. Reef, 2020, Variable impacts of climate change on blue carbon, One Earth 3(2): 195-211.

MacIntyre, H.L, Geider, R.J., and D.C. Miller, 1996, Microphytobenthos: The ecological role of the "secret garden" of unvegetated, shallow-water marine habitats. I. Distribution, abundance, and primary production, Estuaries 19: 186-201.

Macreadie, P.I., et al., 2019, The future of blue carbon science, Nature communications 10(1): 113.

McKew, B.A., Taylor, J.D., McGenity, T.J., and G.J.C. Underwood, 2011, Resistance and resilience of benthic biofilm communities from temperate saltmarsh to desiccation and rewetting, IMSE 5(1): 30.

Mcleod, E., Chmura, G.L., Bouillon, S., Salm, R., Bjork, M, Duarte, C.M., Lovelock, C.E., Schlesinger, W.H., and B.R. Silliman, 2011, A blueprint for blue carbon: toward an improved understanding of the role of vegetated coastal habitats in sequestering $\mathrm{CO} 2$, Frontiers in Ecology and the Environment 9: 552-560.

Middelburg, J.J., Barranguet, C., Boschket, H.T.S., Herman, P.M.J., Moens, T., and Heip, C.H.R., 2000, The fate of intertidal microphytobenthos carbon: an in situ 13C-labeling study, Limnol. Oceanography 45(6): 1224-1234.

Middelburg, J.J., Nieuwenhuize, J., Lubberts, R.K., and O. van der Plassche, 1997, Organic carbon isotope systematics of coastal marshes, Estuarine Coastal Shelf Science 45: 681687.

Miller, D.C., Geider, R.J., and H.L. MacIntyre, 1996, Microphytobenthos: the ecological role of the "secret garden" of unvegetated, shallow-water marine habitats. II. Role in sediment stability and shallow-water food webs, Estuaries 19: 202-212.

Moncreiff, C.A. and M.J. Sullivan, 2001, Trophic importance of epiphytic algae in subtropical seagrass beds: evidence from multiple stable isotope analysis, Marine Ecological Progress Series 215: 93-106.

Murphy, R.J., Tolhurst, T.J., Chapman, M.G., and A.J. Underwood, 2009, Seasonal distribution of chlorophyll on mudflats in New South Wales, Australia measured by field spectrometry and PAM fluorometry, Estuarine, Coastal, and Shelf Science 84: 108-118.

Orvain, F., De Crignis, M., Guizien, K., Lefebvre, S., Mallet, C., Takahashi, E., and C. Dupuy, 2014, Tidal and seasonal effects on the short-term temporal patterns of bacteria, 
This manuscript has been submitted for publication in Wetlands. This manuscript has not yet undergone peer review and is a preprint. Subsequent versions of this manuscript may have slightly different content. If accepted, the final version of this manuscript will be available via the 'Peer-reviewed Publication DOI' link on the right-hand side of this webpage. microphytobenthos, and exopolymers in natural intertidal biofilms (Brouage, France), Journal of Sea Research 92: 6-18.

Orvain, F., Galois, R., and C. Barnard, 2003, Carbohydrate production in relation to microphytobenthic biofilm development: an integrated approach in a tidal mesocosm, Microb. Ecol. 45: 237-251.

Ouyang, X., and S.Y. Lee, 2014, Updated estimates of carbon accumulation rates in coastal marsh sediments, Biogeosciences 11: 5057-5071.

Paterson, D.M., 1989, Short-term changes in the erodibility of intertidal cohesive sediments related to the migratory behavior of epipelic diatoms, Limnology and Oceanography 34(1): 223-234.

Pinckney, J., and R.G. Zingmark, 1993, Biomass and production of benthic microalgal communities in estuarine habitats, Estuaries 16: 887-897.

Pivato, M., Carniello, L., Moro, I., and P. D’Odorico, 2019, On the feedback between water turbidity and microphytobenthos growth in shallow tidal environments, Earth Surface Processes and Landforms 44(5): 1192-1206.

Pomeroy, L., 1969, Algal productivity in salt marshes of Georgia, Limnology Oceanography 4: 386-397.

Ramnarine, R., Voroney, R.B., Wagner-Riddle, C., and K.E. Dunfield, 2011, Carbonate removal by acid fumication for measuring the $\mathrm{C}$ of soil organic carbon, Can. J. Soil Sci., 91: 247250.

Reef, R., Atwood, T.B., Samper-Villarreal, J., Adame, M.F., Sampayo, E.M., and C.E. Lovelock, 2017, Using eDNA to determine the source of organic carbon in seagrass meadows, Limno. Oceanogr. 62: 1254-1265.

Savelli, R., Bertin, X., Orvain, F., Gernez, P., Dale, A., Coulombier, T., Pineau, P., Lachaussee, N., Polsenaere, P., Dupuy, C., and V. Le Fouest, 2019, Impact of chronic and massive resuspension mechanisms on the microphytobenthos dynamics in a temperate intertidal mudflat, JGR Biogeosciences 124(12): 3752-3777.

Serodio, J., Vieira, S., Cruz, S., and F. Barroso, 2005, Short-term variability in the photosynthetic activity of microphytobenthos as detected by measuring rapid light curves using variable fluorescence, Mar. Biol. 146: 903-914.

Shields, M.R., Bianchi, T.S., Mohrig, D., Hutchings, J.A., Kenney, W.F., Kolker, A.S., and J.H. Curtis, 2017, Carbon storage in the Mississippi River delta enhanced by environmental engineering, Nature Geoscience 10: 846-851.

Smith, D.J., and G.J.C. Underwood, 1998, Exopolymer production by intertidal epipelic diatoms, Limnol. Oceanogr. 43: 1578-1591.

Spohn, M. and L. Giani, 2012, Carbohydrates, carbon and nitrogen in soils of a marine and a brackish marsh as influenced by inundation frequency, Estuarine, Coastal and Shelf Science 107: 89-96.

Sprague, L.A., Hirsch, R.M., and B.T. Aulenbach, 2011, Nitrate in the Mississippi River and its tributaries, 1980 to 2008: are we making progress?, Enviorn. Sci. Technol. 45(17): 72097216.

Stagg, C.L. and I.A. Mendelssohn, 2012, Littoraria irrorata growth and survival in a sedimentrestored salt marsh, Wetlands 32: 643-652.

Sutherland, T.F., Amos, C.L., and J. Grant, 1998, The effect of carbohydrate production by the diatom Nitzschia curvilineata on the erodibility of sediment, Limnol. Oceanogr. 43: 6572. 
This manuscript has been submitted for publication in Wetlands. This manuscript has not yet undergone peer review and is a preprint. Subsequent versions of this manuscript may have slightly different content. If accepted, the final version of this manuscript will be available via the 'Peer-reviewed Publication DOI' link on the right-hand side of this webpage.

Tanner, B.R., Uhle, M.E., Mora, C.I., Kelley, J.T., Schuneman, P.J., Lane, C.S., and E.S. Allen, 2010, Comparison of bulk and compound-specific $\partial 13 \mathrm{C}$ analyses and determination of carbon sources to salt marsh sediment using $n$-alkane distributions (Maine, USA), Estuarine, Coastal, and Shelf Science 86(2): 283-291.

Ubertini, M., Lefebvre, S., Gangnery, A., Grangere, K., Le Gendre, R., and F. Orvain, 2012, Spatial variability of benthic-pelagic coupling in an estuary ecosystem: consequences for microphytobenthos resuspension phenomenon, PloS one 7(8): e44155.

Underwood, G.J.C., and J. Kromkamp, 1999, Primary production by phytoplankton and microphytobenthos in estuaries, Adv. Ecol. Res. 29: 93-153.

Underwood, G.J.C., Paterson, D.M., and R.J. Parkes, 1995, The measurement of microbial carbohydrate exopolymers from intertidal sediments, Limnology and Oceanography 40(7): 1243-1253.

Unger, V., Elsey-Quirk, T., Sommerfield, C., and D. Velinsky, 2016, Stability of organic carbon accumulation in Spartina alterniflora-dominated salt marshes of the Mid-Atlantic U.S., Estuarine, Coastal, and Shelf Science 182: 179-189.

Wollenberg, J.T., Ollerhead, J., and G.L. Chmura, 2018, Rapid carbon accumulation following managed realignment on the Bay of Fundy, PloS One 13(3): e0193930.

Zedler, J.B., 1980, Algal mat productivity: comparisons in a salt marsh, Estuaries 3(2): 122-131.

(1)

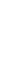

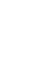

53

6

7

8

9

(1)


This manuscript has been submitted for publication in Wetlands. This manuscript has not yet undergone peer review and is a preprint. Subsequent versions of this manuscript may have slightly different content. If accepted, the final version of this manuscript will be available via the 'Peer-reviewed Publication DOI' link on the right-hand side of this webpage.

Figure Captions:

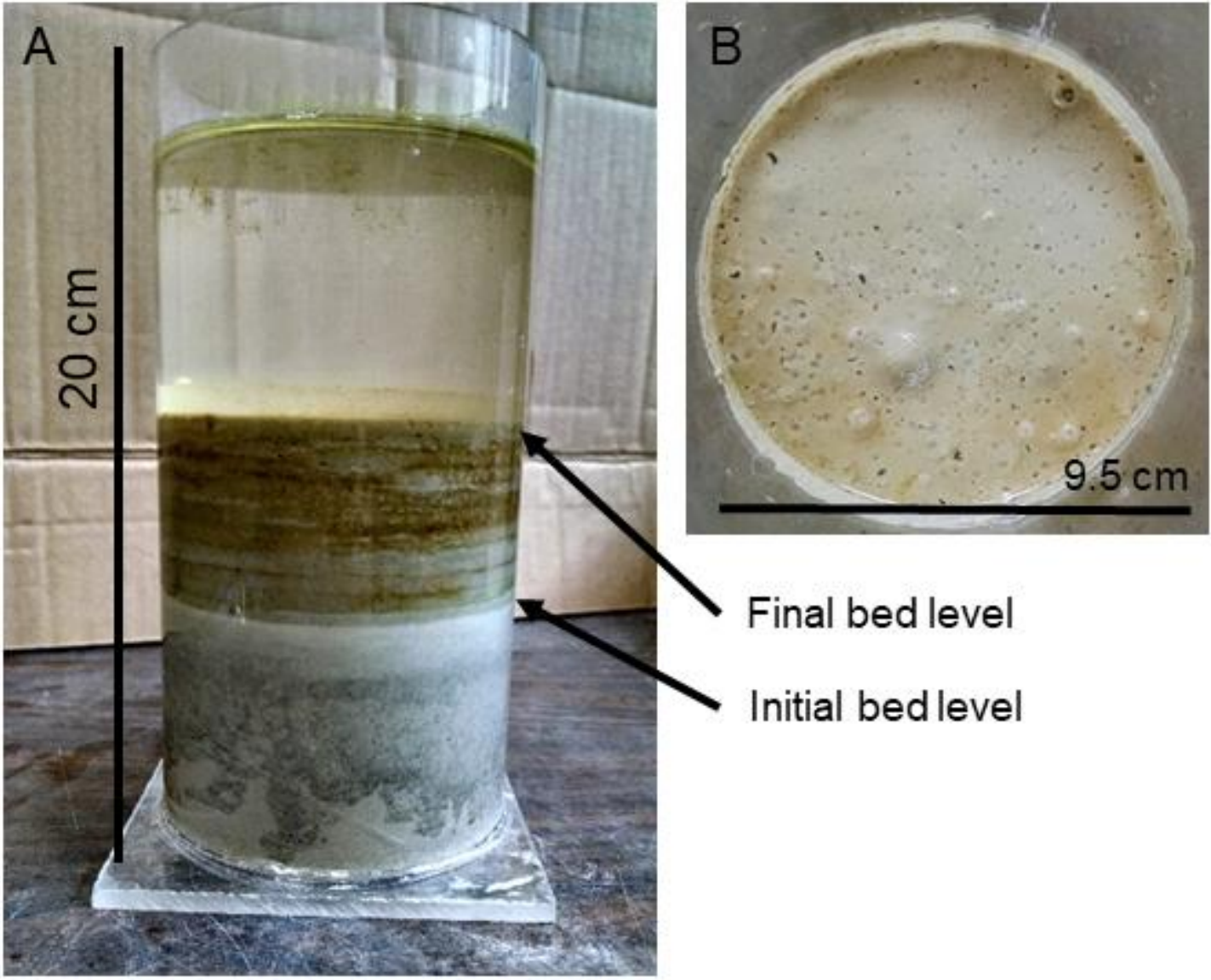

559 Figure 1: Plastic cylinders used for the experiment after 11 weeks of growth. (A) Side view 560 showing the vertical accumulation of sediments. The parallel layers in the sediment, starting at 561 about half of the sediment column, are from individual sedimentation events and subsequent 562 growth of biofilm. (B) Plane-view of growth experiment. Light brown color is indicative of 563 diatom-based biofilm. 
This manuscript has been submitted for publication in Wetlands. This manuscript has not yet undergone peer review and is a preprint. Subsequent versions of this manuscript may have slightly different content. If accepted, the final version of this manuscript will be available via the 'Peer-reviewed Publication DOI' link on the right-hand side of this webpage.
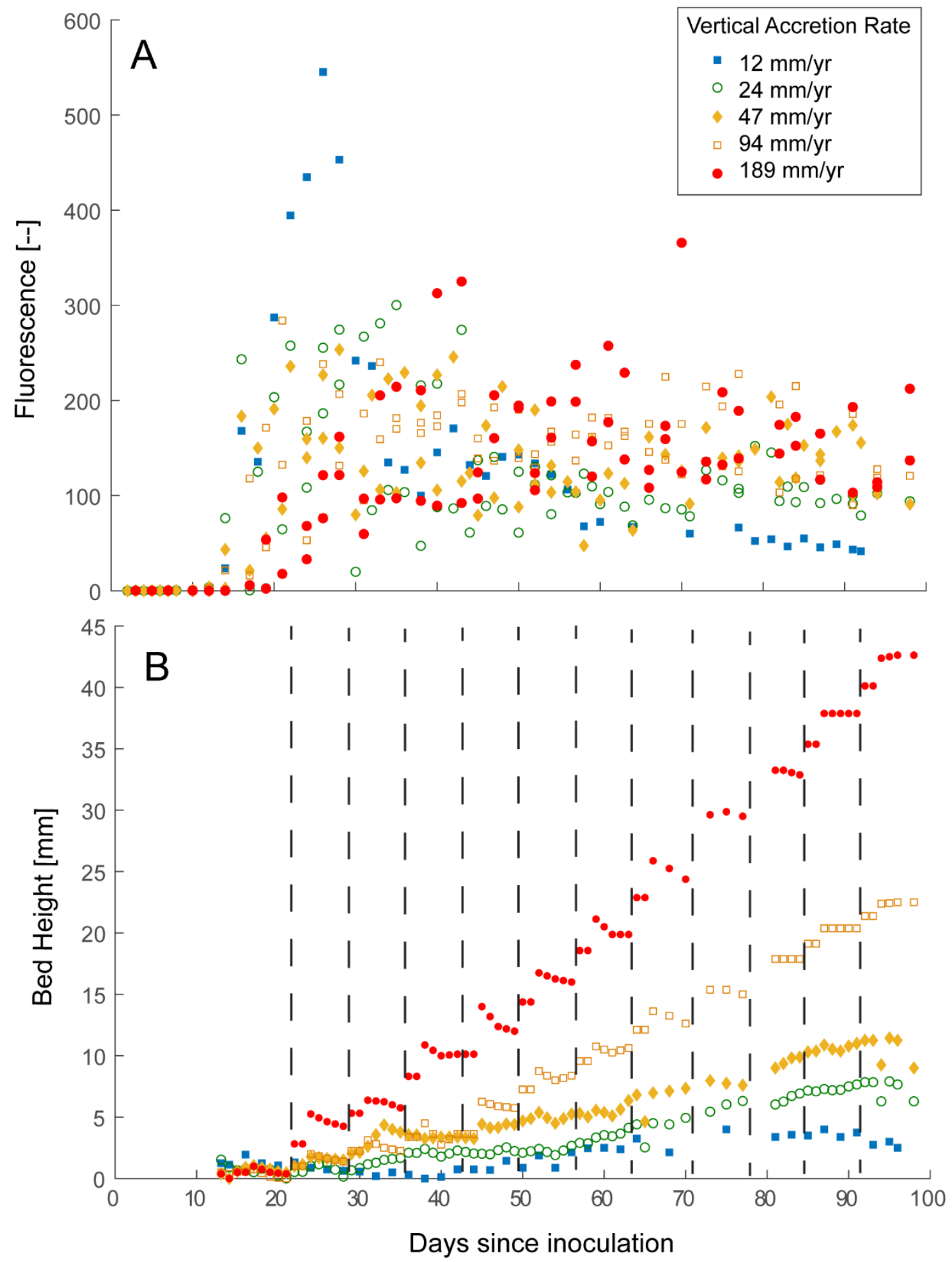

Days since inoculation

566 Figure 2: Monitoring of fluorescence (A) and bed height (B) over the 11-week experiment.

567 Colors represent the five different sedimentation rates (see Table 1). Fluorescence measurements

568 are consistent across treatments. Bed height measurements were corrected for the consolidation

569 of the initial bed over time. Vertical lines in panel B indicate when sediment was added to the

570 experiment.

571 
This manuscript has been submitted for publication in Wetlands. This manuscript has not yet undergone peer review and is a preprint. Subsequent versions of this manuscript may have slightly different content. If accepted, the final version of this manuscript will be available via the 'Peer-reviewed Publication DOI' link on the right-hand side of this webpage.
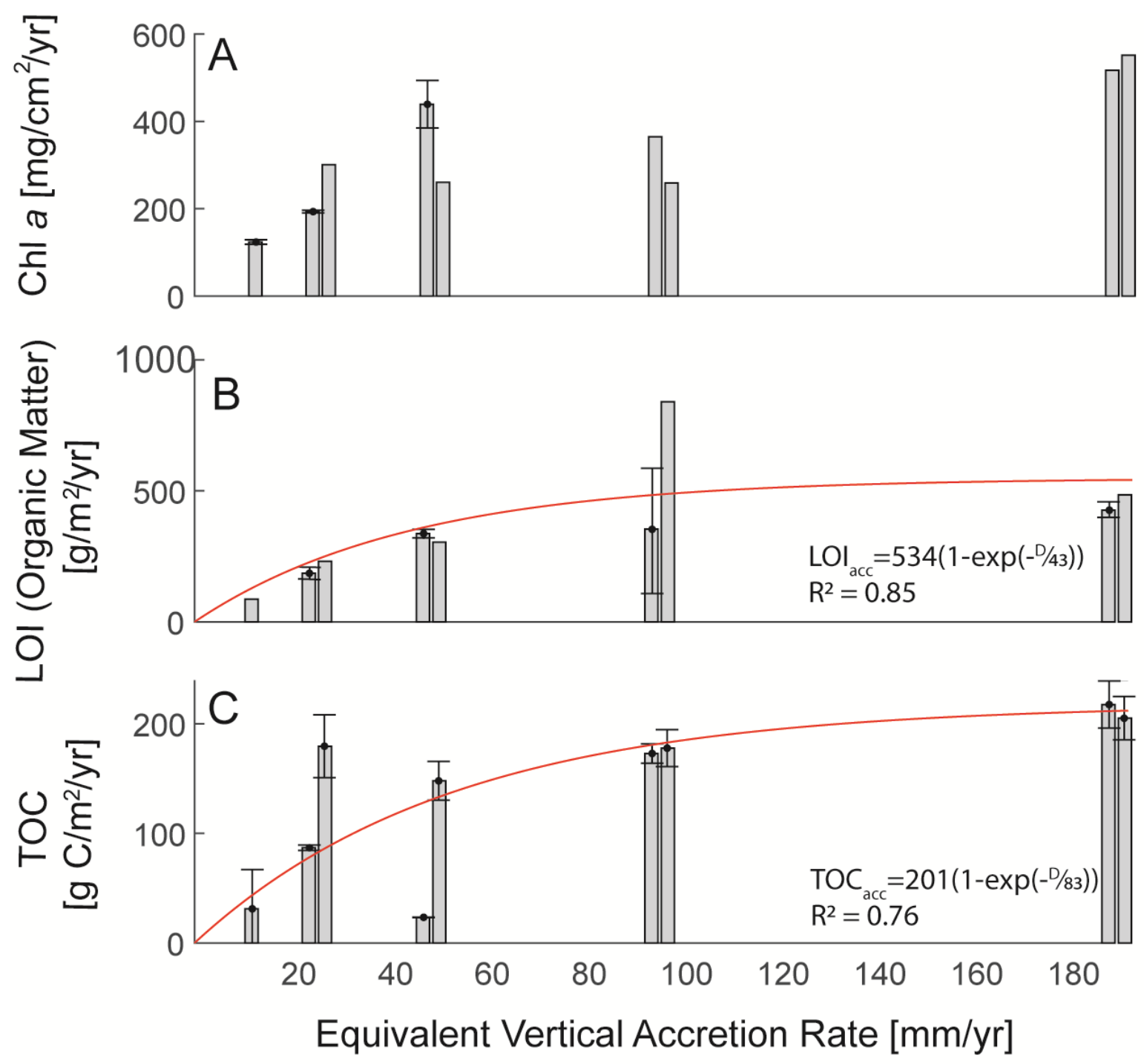

572

573

574

575

576

577

578
Figure 3: Chl $a$ (A), LOI (B), and TOC (C) values for the content of the containers following the 11-week growth experiment for each of the five growth rates. All three metrics show an increase with equivalent vertical accretion rate. Duplicate bars indicate separate trials, standard deviations show measurement variability. Lines in (B) and (C) show best fit to equation 1. (B) $R^{2}=0.85$ and $(\mathrm{C}) \mathrm{R}^{2}=0.76$. 
This manuscript has been submitted for publication in Wetlands. This manuscript has not yet undergone peer review and is a preprint. Subsequent versions of this manuscript may have slightly different content. If accepted, the final version of this manuscript will be available via the 'Peer-reviewed Publication DOI' link on the right-hand side of this webpage.

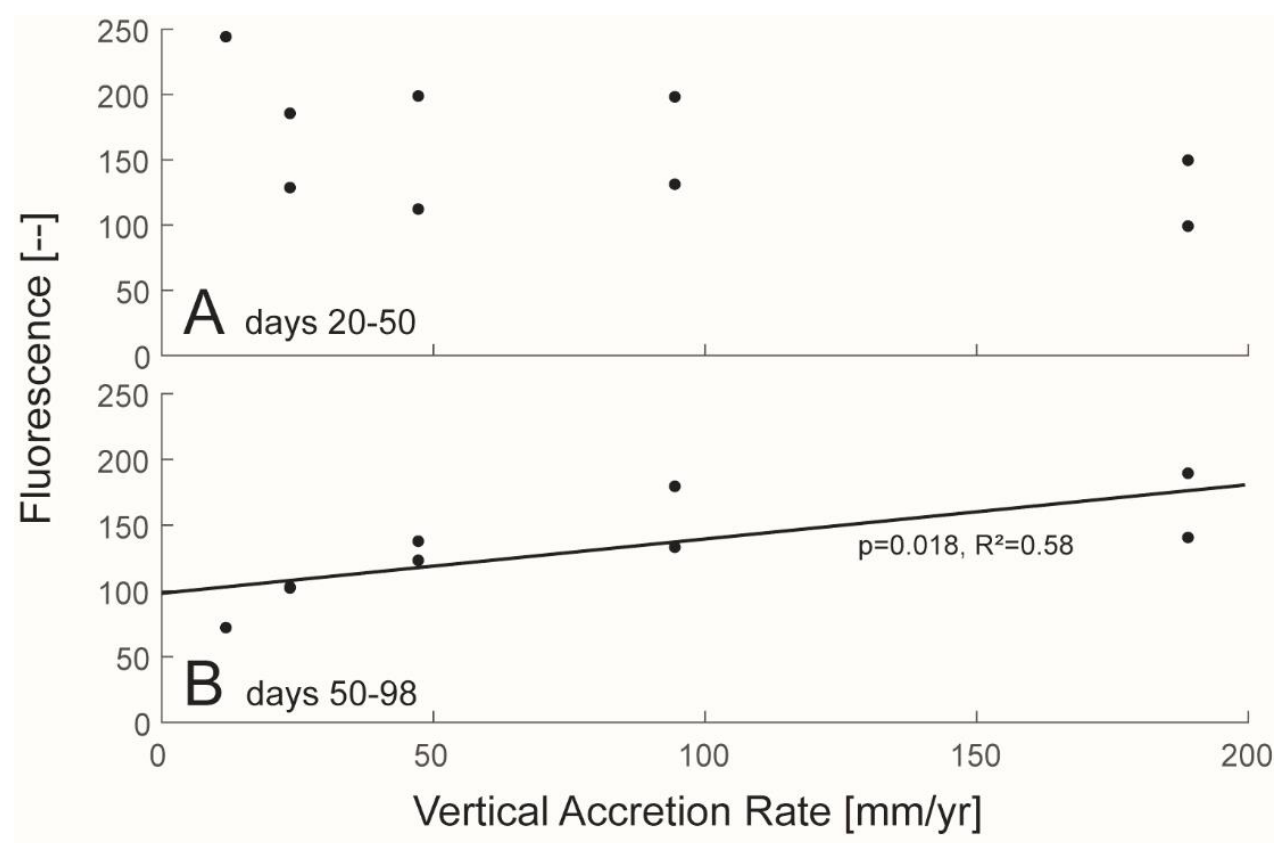

Figure 4: Average PAM fluorescence value by sedimentation rate for days 20-50 (A) and 50-98 (B). There was no statistically significant relationship between fluorescence and sedimentation rate in the beginning of the experiments, but in days 50-98, there was a significant linear relationship $\left(\mathrm{y}=0.41 \mathrm{x}+98, \mathrm{R}^{2}=0.5, \mathrm{p}=0.018\right)$.

Table 1: List of treatments, or sedimentation rates used in this experiment.

\begin{tabular}{|l|l|l|l|}
\hline $\begin{array}{l}\text { Sedimentation } \\
\text { Rank }\end{array}$ & $\begin{array}{l}\text { Mass added each week } \\
(\mathrm{g})\end{array}$ & $\begin{array}{l}\text { Sedimentation Rate } \\
2 \\
(\mathrm{~g} / \mathrm{cm} / \mathrm{yr})\end{array}$ & $\begin{array}{l}\text { Equivalent Vertical } \\
\text { Accretion Rate }(\mathrm{mm} / \mathrm{yr})\end{array}$ \\
\hline 1 & 1.069 & 0.786 & 11.811 \\
\hline 2 & 2.137 & 1.572 & 23.612 \\
\hline 3 & 4.273 & 3.144 & 47.222 \\
\hline 4 & 8.547 & 6.287 & 94.444 \\
\hline 5 & 17.093 & 12.574 & 188.889 \\
\hline
\end{tabular}

